\title{
Anterior cervical pedicle screw and plate fixation using fluoroscope-assisted pedicle axis view imaging: a preliminary report of a new cervical reconstruction technique
}

\author{
Yasutsugu Yukawa - Fumihiko Kato · \\ Keigo Ito · Hiroaki Nakashima · Masaaki Machino
}

Received: 11 July 2008/Revised: 3 March 2009/Accepted: 12 March 2009/Published online: 3 April 2009

(C) Springer-Verlag 2009

\begin{abstract}
Anterior procedures in the cervical spine are feasible in cases having anterior aetiologies such as anterior neural compression and/or severe kyphosis. Halo vests or anterior plates are used concurrently for cases with long segmental fixation. Halo vests are bothersome and anterior plate fixation is not adequately durable. We developed a new anterior pedicle screw (APS) and plate fixation procedure that can be used with fluoroscope-assisted pedicle axis view imaging. Six patients ( 3 men and 3 women; mean age, 54 years) with anterior multisegmental aetiology were included in this study. Their original diagnoses comprised cervical myelopathy and/or radiculopathy $(n=4)$, posterior longitudinal ligament ossification $(n=1)$ and posttraumatic kyphosis $(n=1)$. All patients underwent anterior decompression and strut grafting with APS and plate fixation. Mean operative time was $192 \mathrm{~min}$ and average blood loss was $73 \mathrm{ml}$. Patients were permitted to ambulate the next day with a cervical collar. Local sagittal alignment was characterised by $3.5^{\circ}$ of kyphosis preoperatively, which improved to $6.8^{\circ}$ of lordosis postoperatively and $5.2^{\circ}$ of lordosis at final follow-up. Postoperative improvement and early bony union were observed in all cases. There was no serious complication except for two cases of dysphagia. Postoperative imaging demonstrated screw exposure in one screw, but no pedicle perforation. APS and plate fixation is useful in selected cases of multisegmental anterior reconstruction of cervical spine. However, the adequate familiarity and experience with both cervical pedicle screw fixation and the imaging
\end{abstract}

Y. Yukawa $(\bowtie) \cdot$ F. Kato $\cdot$ K. Ito $\cdot$ H. Nakashima

M. Machino

Department of Orthopedic Surgery, Chubu Rosai Hospital, 1-10-6 Komei, Minato-ku, Nagoya, Aichi 455-0018, Japan e-mail: yukawa.ort@chubuh.rofuku.go.jp technique used for visualising the pedicle during surgery are crucial for this procedure.

Keywords Anterior pedicle screw - Cervical spine . Pedicle axis view - Fluoroscope

\section{Introduction}

In cervical spine reconstruction, the posterior pedicle screw (PPS) fixation technique was first used to treat injuries/ pathology in mid- to lower cervical vertebrae by Abumi et al. [1]. Since then, there has been extensive literature on the ex vivo anatomical and in vivo clinical feasibility of PPS [2, 3, 31, 32]. In experimental studies, cervical pedicle screw fixation has been reported to provide the greatest stability to an unstable cervical spine $[11,16,18]$. Pedicle screw fixation has generally been considered to be very risky because it can seriously injure vertebral arteries, the spinal cord or nerve roots. Therefore, if the safety of the procedure improves, cervical pedicle screw fixation can be effective in reconstructing the cervical spine.

Many cases have required multilevel anterior decompression and reconstruction. In these cases, the fusion and complication rates at the anterior cervical spine have been shown to have a direct correlation with the mechanical stability of fixation. However, in anterior cervical spine surgery following one-level three-column injuries $[8,30]$ or multilevel discectomies and corpectomies $[5,6,19,23$, $28,29]$, the biomechanical stability of the anterior cervical spine screw and plate system is limited. In such cases, supplemental posterior stabilization is often needed. To avoid the need for additional posterior stabilization in patients who are scheduled to undergo anterior reconstructive surgery, an anterior cervical spine implant 
offering higher primary stability is desirable, but in selected cases.

Cervical spine pedicles are strong structural elements that act as rigid anchorage for instrumentation. In 1995, we developed a pedicle axis view technique to accurately insert the posterior cervical pedicle screw and have used it in more than 200 cases [32]. This technique allowed us to insert the anterior pedicle screw (APS) as accurately as PPS. We have employed pedicle screw fixation in selected anterior cervical surgeries since 2006. In this study, we use a surgical technique for APS and plate fixation (APSPF) in six patients and report their preliminary outcomes.

\section{Materials and methods}

Six patients [3 men and 3 women; mean age, 54 years (range 34-74)] who underwent APSPF in 2006 and 2007 were included in this study. These cases accounted for $23 \%$ of all anterior cervical fixation cases (6/26) and $1.5 \%$ of all cervical spine surgery cases (6/396) in 2006 and 2007 at our institution. All patients had two or more levels of anterior pathological disorders that could not be treated with posterior surgery alone. They were originally diagnosed with cervical spondylotic myelopathy and/or radiculopathy $(n=4)$, posterior longitudinal ligament ossification $(n=1)$ and post-traumatic kyphosis $(n=1)$.

Plain radiographs [anteroposterior (AP), lateral and two oblique views], computed tomography (CT) scans and magnetic resonance (MR) images were obtained preoperatively in all patients. Pedicle morphology and medial inclination of pedicle axis were fully visualised. The narrowest pedicle diameter was confirmed to be more than $4.0 \mathrm{~mm}$. In all cases, MR and/or CT angiography was performed to visualise vertebral arteries, and the patency of bilateral vertebral arteries was confirmed.

Preoperative and postoperative neurological status was evaluated according to the Japanese Orthopaedic Association (JOA) scores for cervical myelopathy [33]. Improvement in postoperative symptomatology was evaluated using the recovery rate of the JOA score [(postoperative JOA score - preoperative JOA score)/ $(17$ - preoperative JOA score $) \times 100 \%$ ]; a recovery rate of $100 \%$ indicated the best postoperative improvement.

Surgical procedure

All patients were placed on surgical beds in the supine position with the neck slightly extended and the head fixed with tape (Fig. 1). The surgical level of the cervical spine was positioned as parallel to the floor as possible to facilitate handling of the fluoroscope. The shoulder girdles were pulled caudally and immobilised by tape. The pedicle axis view at the surgical level was confirmed preoperatively. The anterior surgical site was exposed one level above the decompression lesion and one below by a left oblique incision. After performing subtotal corpectomy, decompression and strut grafting using the iliac bone or fibula, cervical pedicle screws were inserted with the assistance of intraoperative fluoroscopic imaging. First, a multiplanar fluoroscope was set on the left side of the patient to obtain an accurate lateral view of the cervical spine; then, this fluoroscope was rotated until it depicted the approximate circular portion of the right pedicle cortex in the transverse plane of the vertebral body (Fig. 2a), setting the axis of rotation to a cervical longitudinal axis. In lower cervical spine cases where good lateral views were not obtained because of the overlying shoulders, the pedicle axis view indicated the pedicle entry point. The pedicle axis was normally inclined at $35^{\circ}-50^{\circ}$ from the mid-sagittal plane (C3-7) (Fig. 3) [12, 20-22]. The authors used a screw trajectory angle of $45^{\circ}$ from the sagittal plane for C3-6 and $40^{\circ}$ for $\mathrm{C} 7$. The centre of the cortical circular area visualised with the image intensifier indicated the insertion point of the screw on the vertebral body (Fig. 2a). There is typically about $2 \mathrm{~mm}$ of surface area below the upper end, central to the transverse plane; the entry hole was created with a straight awl. Subsequently, a $1.4 \mathrm{~mm}$ guidewire of cannulated screw was inserted into the pedicle cavity using a drill, with a $45^{\circ}$ inclination from the sagittal plane. The trajectory angle conformed to the $\mathrm{C}$-arm beam angle of the fluoroscope. The placement of guidewires was confirmed repeatedly on AP, lateral and pedicle axis views by fluoroscopy (Fig. 2b). If the guidewires migrated outside the pedicle, insertion was reattempted to create a correct pathway. After inserting guidewires at each level (Fig. 2c), tapping was performed. Precise length of the plates (axis plate) was selected and bent along the contour of the physiological lordosis (Fig. 2d). The diameter of cannulated (pedicle) screws was $4 \mathrm{~mm}$ and the length ranged from 30 to $34 \mathrm{~mm}$.

\section{Postoperative assessment of screw placement}

The accuracy of pedicle screw placement was examined postoperatively by reviewing axial CT scans (1 mm slice thickness) and oblique radiographs. The relationship between pedicle screws and medial/lateral pedicle walls was examined on CT scans, whereas superior/inferior pedicle wall screw locations were examined on oblique radiographs. An independent radiologist assessed the position of cervical pedicle screws. Screw malpositioning was classified as 'screw exposure' (non-critical breach) or 'pedicle perforation' (risk for neurovascular injury) [32]. Screw exposure occurred when the pedicle screws breached the pedicle wall with more than $50 \%$ of screw 


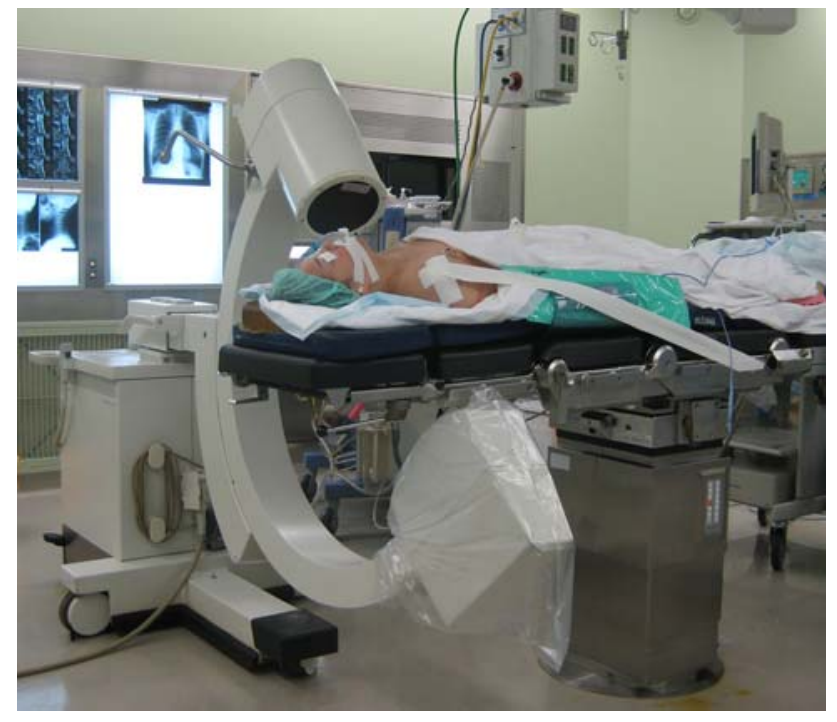

Fig. 1 Illustrative setting of patient and fluoroscope to obtain the appropriate pedicle axis view

diameter remaining within the pedicle. Pedicle perforation occurred when the pedicle screws breached the pedicle wall with more than $50 \%$ of screw diameter outside the pedicle.

\section{Results}

Mean operative time was $192 \mathrm{~min}$ (range 142-235 min) and average blood loss was $73 \mathrm{ml}$ (range 20-150 ml). There were two fixation levels in five cases and three in one case. All patients were permitted to ambulate the next day

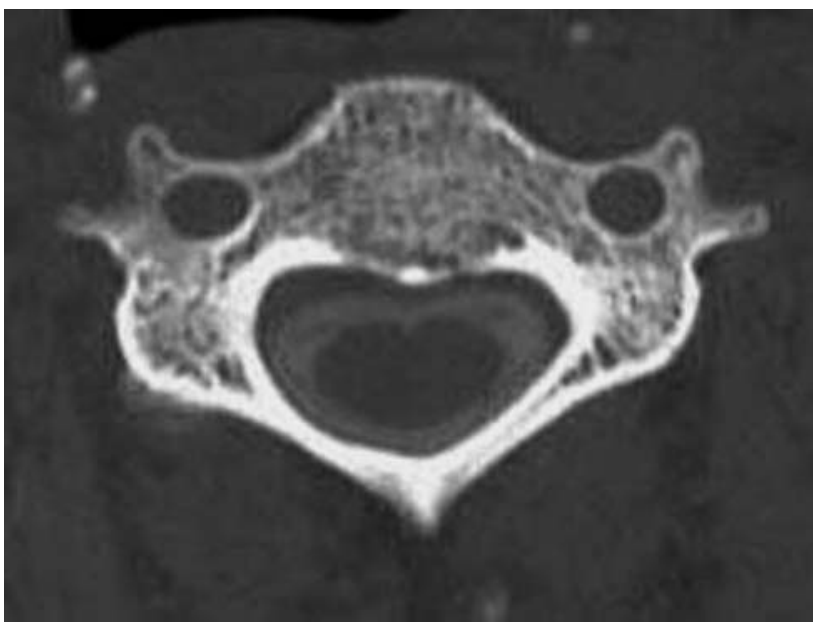

Fig. 3 Axial CT of C5

with a cervical collar. This orthosis was used for 1 month for four cases and 2 months for two cases. All cases were followed up at more than 6 months, and the mean followup period was 12.2 months (range 7-21 months). The mean JOA score was 12.0 preoperatively and 14.7 postoperatively. The mean recovery rate of JOA score was $51.4 \%$ at final follow-up. The average local alignment, which was characterised by $3.5^{\circ}$ of kyphosis preoperatively, improved to $6.8^{\circ}$ of lordosis postoperatively and $5.2^{\circ}$ of lordosis at final follow-up. Postoperative improvement and early bony union were observed in all cases. There was no serious complication, except for two cases of dysphagia. Seventeen APSs were used. Postoperative imaging demonstrated screw exposure in one screw, but no pedicle perforation.
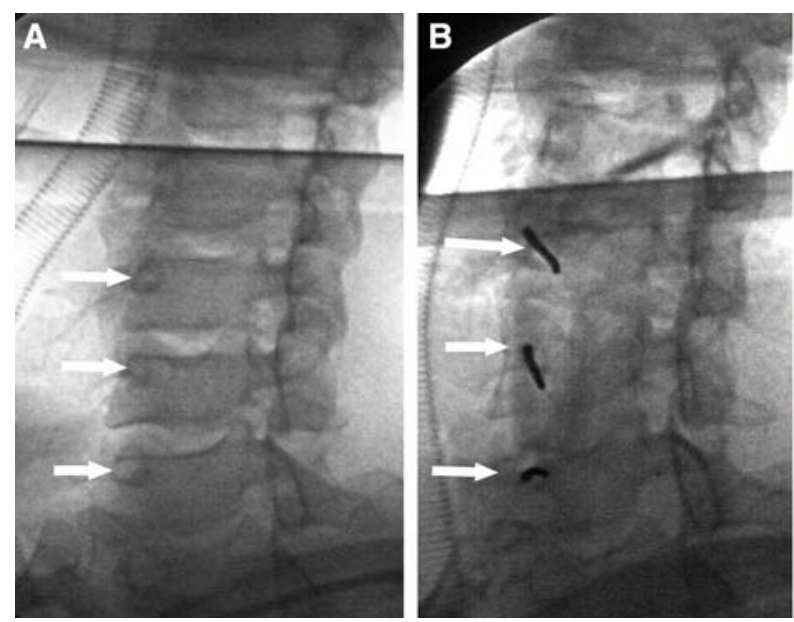

Fig. 2 Intraoperative fluoroscopic imaging. a Oblique radiograph showing the cortical circles of right C3-7 pedicles. Right C5-7 pedicles can be seen as a round circle just below the upper endplate and this is the pedicle axis view (arrows). b Guidewires inserted in
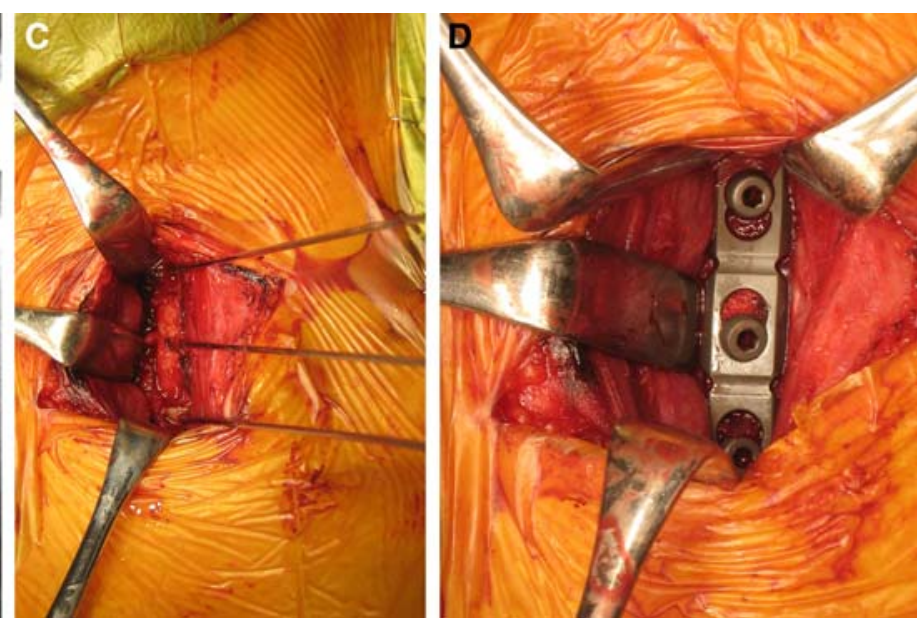

C5-7 pedicles (arrow). c Intraoperative image showing the guidewires inserted in C5-7 pedicles. d Intraoperative image after C5-7 plate and screw fixation 


\section{Illustrative case}

A 34-year-old woman sustained a C5 fracture (compressive flexion, stage 3 according to the classification by Allen et al. [4]). She had ASIA-D neurological deficit. Conservative treatment with a hard collar was given at another hospital. Three months after the injury, she consulted our hospital with residual neck pain and progressive kyphotic deformity. Anterior decompression, fusion and fixation of C5-7 were performed by APSPF using the pedicle axis view technique. Postoperative plain radiographs and MR and CT images showed good cervical alignment and accurate placement of pedicle screws within the pedicle cortex (Fig. 4a-g).

\section{Discussion}

The purpose of this study was to introduce the use of APSPF aided by fluoroscope-assisted pedicle axis view imaging in the cervical spine. This paper is also a preliminary report of the clinical application and surgical outcome of APSPF in the cervical spine. The results demonstrate that this technique resulted in a feasible surgical outcome in selected cases as long as pedicle axis view imaging was concurrently used. However, this technique cannot act as a replacement to common techniques for daily cervical spine surgery but is rather appropriate as a technical adjunct for selected cases.

Cervical spine reconstruction can be performed via three approaches: anterior, posterior and combined anteriorposterior. Previous experimental studies demonstrated that PPS fixation provided the strongest stability amongst all cervical instrumentations. Therefore, pedicle screw fixation provides strong fixation for posterior decompression. However, some cases require multilevel anterior decompression. Unfortunately, long strut grafts or cages used for the reconstruction are biomechanically inferior [25] and vulnerable to failure, and therefore, require revision [5, 7]. A literature review [13] showed that the rate of non-union in multilevel ACDF is as high as $20-50 \%$, and the failure rate for long-length decompression or corpectomies ranged
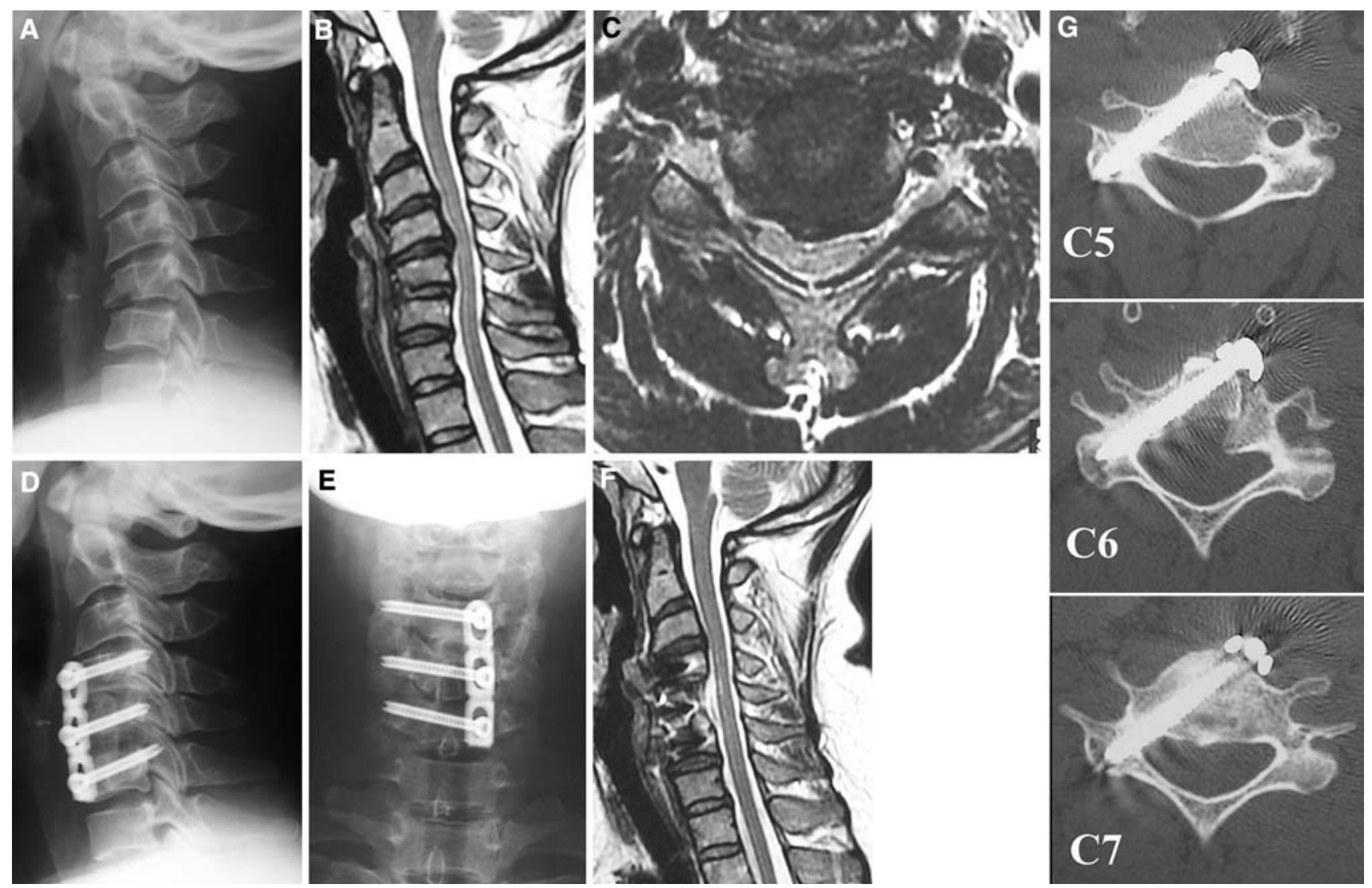

Fig. 4 Imaging studies of the illustrative case. a Preoperative lateral radiograph showing C5 compression fracture and kyphotic deformity. b, c T2 sagittal and axial images of MR demonstrating spinal cord compression and obscure changes in cord signals. d, e Postoperative AP and lateral radiographs showing good alignment and C4-6 pedicle screw fixation. f Postoperative T2 sagittal image of MR showing good decompression and neutral alignment. g Postoperative axial CT demonstrating good placement of anterior pedicle screws at C4-6 levels 
from 30 to $100 \%$ [19, 23, 24, 29]. Therefore, biomechanical studies and clinical series support employing additional posterior stabilization or external fixation (e.g. halo vests) in multilevel procedures to improve early- and long-term stability [26, 28]. However, with the biomechanical advantage of supplemental posterior stabilization comes the necessity of a second approach, added surgical risks and a higher rate of infection. Moreover, although the application of a halo vest might decrease the chances of instrumentation failure, it is extremely uncomfortable for patients. These situations have demanded an increase in the primary rigidity of an anterior-only fusion construct. A new concept that combined the advantages of an anterior approach and superior biomechanical characteristics of cervical pedicle screw fixation was derived.

The biomechanical characteristics of APS need to be investigated before its use in a clinical setup. Koller et al. [14] demonstrated that the pull-out strength of APS (mean, $468 \mathrm{~N}$ ) was about 2.5 times that of a vertebral body screw (mean $182 \mathrm{~N}$ ) in their cadaver experiment. In addition, because of the pedicle-vertebra morphology, APS fixation can be used with vertebral body screw at each cervical vertebra along with the newly developed anterior plates [15]. Another advantage is that segmental pedicle screw fixation can be performed at each level even via grafted bone for reconstruction after long segmental corpectomy, unlike regular anterior plate fixation. Although the pull-out strength of APS was higher than that of vertebral body screws, its resistance to rotation or bending has not been elucidated. To investigate this aspect and to aid the development of instrumentation in the next stage, further experimental studies should be conducted.

APS and plate fixation poses a potential risk for injury to vertebral arteries, the spinal cord or nerve roots. The safety of this procedure depends on the placement of screws. The fluoroscopy-assisted pedicle axis view technique helped determine the appropriate entry point that coincided with the correct trajectory angle for each cervical vertebra in sagittal as well as transverse planes. The advantage of this technique is the simultaneous indication of the insertion point as well as the trajectory angle of screws; if either is not correct, pedicle perforation is likely to occur. In our experience of PPS procedures, critical breaches were seen in 17 (4.0\%) of 419 screws [32], and all these displaced screws were clinically silent. Although the neurovascular surroundings of cervical pedicles allow for some safety margin, with most pedicle wall perforations being non-critical $[9,10,12,27,31]$, the potentially fatal consequences of neurovascular injury during APS insertion remain a serious concern. Injury to the vertebral artery may cause cerebral infarction or death. If apparent dominance or angiectopia of the vertebral artery is seen in preoperative imaging, this procedure should be performed on the contralateral side or abandoned until an accurate image-assisting system is developed. APSPF should be used in selected cases that demand anterior reconstruction despite severe osteoporosis or revision after conventional plate fixation failure ( $\geq 2$ levels).

Computerised navigation systems, mobile CT technology in particular, may increase the accuracy of APS insertion. However, these systems are not installed in most hospitals because they are not cost-effective and userfriendly. A more accurate, user-friendly and real-time navigation system should be developed for clinical practice in the future.

The main limitation of this study was the small samplesize. This technique demands a high level of surgical skill and has relatively higher risks, and hence, cases were chosen selectively. The present six cases accounted for only $1.5 \%$ of all the cases, who underwent cervical spine surgeries in our hospital from 2006 to 2007. The preliminary series included two- or three-level fixation cases. These patients could have also been treated with conventional plate/screw fixation. APSPF procedure could prove its merits by being used in long segmental fixation at several levels, e.g. 4 or 5 . This should be validated in the next step. The instruments used for these cases were lateral mass plate and transarticular screw that are generally used in the Magerl procedure. However, the screw head protruded anteriorly and induced dysphagia in two of the six cases. Dedicated instrumentation for APSPF is currently under construction and is expected to be developed soon. The APSPF technique demands great understanding of and familiarity with cervical anatomy, as well as experience with PPS and special imaging techniques. Development of surgical techniques and imaging instruments should improve the accuracy of screw placement. APSPF should not be considered a routine surgical procedure; rather it should be the one of the surgical options offering the strongest fixation in anterior cervical reconstruction.

\section{References}

1. Abumi K, Itoh H, Taneichi H, Kaneda K (1994) Transpedicular screw fixation for traumatic lesions of the middle and lower cervical spine: description of the techniques and preliminary report. J Spinal Disord 7:19-28. doi:10.1097/00002517199407010-00003

2. Abumi K, Kaneda K (1997) Pedicle screw fixation for nontraumatic lesions of the cervical spine. Spine 22:1853-1863. doi:10.1097/00007632-199708150-00010

3. Abumi K, Shono Y, Ito M, Taneichi H, Kotani Y, Kaneda K (2000) Complications of pedicle screw fixation in reconstructive surgery of the cervical spine. Spine 25:962-969. doi:10.1097/ 00007632-200004150-00011 
4. Allen BL Jr, Ferguson RL, Lehmann TR, O’Brien RP (1982) A mechanistic classification of closed, indirect fractures and dislocations of the lower cervical spine. Spine 7:1-27

5. Bolesta MJ, Rechtine DR II, Chrin AM (2000) Three- and fourlevel anterior cervical discectomy and fusion with plate fixation: a prospective study. Spine 25:2040-2056. doi:10.1097/ 00007632-200008150-00007

6. Daubs MD (2005) Early failures following cervical corpectomy reconstruction with titanium mesh cages and anterior plating. Spine 30:1402-1406. doi:10.1097/01.brs.0000166526.78058.3c

7. DiAngelo DJ, Foley KT, Vossel KA, Rampersaud YR, Jansen TH (2000) Anterior cervical plating reverses load transfer in multilevel strut graft. Spine 25:2366-2376. doi:10.1097/00007632200004010-00005

8. Henriques T, Olerud C, Bergman A, Jonsson H Jr (2004) Distractive flexion injuries of the subaxial cervical spine treated with anterior plate alone. J Spinal Disord Tech 17:1-7. doi:10.1097/ 00024720-200402000-00002

9. Ito $\mathrm{H}$, Neo M, Yoshida M, Fujibayashi S, Yoshitomi H, Nakamura T (2006) Efficacy of computer-assisted pedicle screw insertion for cervical instability in RA patients. Rheumatol Int 27:567-574. doi:10.1007/s00296-006-0256-7

10. Jeanneret B, Gebhard JS, Magerl F (1994) Transpedicular screw fixation of articular mass fracture-separation: results of an anatomical study and operative technique. Spine 19:2529-2539

11. Jones EL, Heller JG, Silcox DH, Hutton WC (1997) Cervical pedicle screws versus lateral mass screws. Anatomic feasibility and biomechanical comparison. Spine 22:977-982. doi:10.1097/ 00007632-199705010-00009

12. Karaikovic EE, Daubs MD, Madsen RW, Gaines RW Jr (1997) Morphologic characteristics of human cervical pedicles. Spine 22:493-500. doi:10.1097/00007632-199703010-00005

13. Koller H, Hempfing A, Ferraris L, Meier O, Metz-Stavenhagen P (2007) 4- and 5-level anterior fusions of the cervical spine: review of literature and clinical results. Eur Spine J 16:20552071. doi:10.1007/s00586-007-0398-7

14. Koller H, Hempfing A, Acosta F, Fox M, Scheiter A, Tauber M, Holz U, Resch H, Hitzl W (2008) Cervical anterior transpedicular screw fixation. Part I: study on morphological feasibility, indications, and technical prerequisites. Eur Spine J 17:523-538. doi:10.1007/s00586-007-0572-y

15. Koller H, Acosta F, Tauber M, Fox M, Martin H, Forstner R, Augat P, Penzkofer R, Pirich C, Kässmann H, Resch H, Hitzl W (2008) Cervical anterior transpedicular screw fixation (ATPS) Part II. Accuracy of manual insertion and pull-out strength of ATPS. Eur Spine J 17:539-555. doi:10.1007/s00586-007-0573-x

16. Kotani Y, Cunningham BW, Abumi K, McAfee PC (1994) Biomechanical analysis of cervical stabilization systems. An assessment of transpedicular screw fixation in the cervical spine. Spine 19:2529-2539. doi:10.1097/00007632-199411001-00007

17. Kotani Y, Abumi K, Ito M, Minami A (2003) Improved accuracy of computer-assisted cervical pedicle screw insertion. J Neurosurg 99(3)(Suppl):257-263

18. Kothe R, Rüter W, Schneider E, Linke B (2004) Biomechanical analysis of transpedicular screw fixation in the subaxial cervical spine. Spine 29:1869-1875. doi:10.1097/01.brs.0000137287. 67388.0b

19. Lowery GL, McDonough RF (1998) The significance of hardware failure in anterior cervical plate fixation. Patients with 2- to 7-year follow-up. Spine 23:181-186. doi:10.1097/00007632199801150-00006

20. Ludwig SC, Kramer DL, Vaccaro AR, Albert TJ (1999) Transpedicle screw fixation of the cervical spine. Clin Orthop Relat Res 359:77-88. Review. doi:10.1097/00003086-19990200000009

21. Panjabi MM, Shin EK, Chen NC, Wang JL (2000) Internal morphology of human cervical pedicles. Spine 25:1197-1205. doi:10.1097/00007632-200005150-00002

22. Sakamoto T, Neo M, Nakamura T (2004) Transpedicular screw placement evaluated by axial computed tomography of the cervical pedicle. Spine 29:2510-2514. discussion 2515. doi:10.1097/ 01.brs.0000144404.68486.85

23. Sasso RC, Ruggiero RA Jr, Reilly TM, Hall PV (2003) Early reconstruction failures after multilevel cervical corpectomy. Spine 28:140-142. doi:10.1097/00007632-200301150-00009

24. Schmidt R, Wilke HJ, Claes L, Puhl W, Richter M (2003) Pedicle screws enhance primary stability in multilevel cervical corporectomies: biomechanical in vitro comparison of different implants including constrained and nonconstrained posterior instruments. Spine 28:1821-1828. doi:10.1097/01.BRS.00000 83287.23521 .48

25. Singh K, Vaccaro AR, Kim J, Lorenz EP, Lim TH, An HS (2004) Enhancement of stability following anterior cervical corpectomy: a biomechanical study. Spine 29:845-849. doi:10.1097/0000 7632-200404150-00005

26. Swank ML, Sutterlin CE 3rd, Bossons CR, Dials BE (1997) Rigid internal fixation with lateral mass plates in multilevel anterior and posterior reconstruction of the cervical spine. Spine 22:274-282. doi:10.1097/00007632-199702010-00009

27. Takahashi J, Shono Z, Nakamura I, Hirabayashi H, Kamimura M, Ebara S, Kato H (2006) Computer-assisted screw insertion of cervical disorders in rheumatoid arthritis. Eur Spine J 16:485494. doi:10.1007/s00586-006-0234-5

28. Ulrich C, Arand M, Nothwang J (2001) Internal fixation on the lower cervical spine-biomechanics and clinical practice of procedures and implants. Eur Spine J 10:88-100. doi:10.1007/ s005860000233

29. Vaccaro AR, Falatyn SP, Scuderi GJ, Eismont FJ, McGuire RA, Singh K, Garfin SR (1998) Early failure of a long segment anterior plate fixation. J Spinal Disord 11(5):410-415. doi:10.1097/00002517-199810000-00008

30. Vecsei V, Fuchs M, Gäbler CH (1998) Indications for treatment of severe unstable injuries of the cervical spine by combined anterior and posterior internal fixation. Osteos Intern 6:121-128

31. Yoshimoto H, Sato S, Hyakumachi T, Yanagibashi Y, Masuda T (2005) Spinal reconstruction using a cervical pedicle screw system. Clin Orthop Relat Res 431:111-119. doi:10.1097/ 01.blo.0000150321.81088.ab

32. Yukawa Y, Kato F, Yoshirara H, Yanase M, Ito K (2006) Cervical pedicle screw fixation in 100 cases of unstable cervical injuries: pedicle axis views obtained using fluoroscopy. J Neurosurg Spine 5:488-493. doi:10.3171/spi.2006.5.6.488

33. Zeidman SM (2005) Evaluation of patients with cervical spine lesions. In: Clark CR (ed) The cervical spine, 4th edn. Philadelphia, Lippincott-Raven Publishers, pp 149-165 